\title{
EMERGÊNCIA DE PLÂNTULAS E CRESCIMENTO DE MUDAS DE JATOBÁ COM USO DE BIOESTIMULANTE E SOMBREAMENTO
}

\author{
Luciane Pierezan ${ }^{1}$, Silvana de Paula Quintão Scalon², Zefa Valdivina Pereira ${ }^{3}$
}

(recebido: 27 de janeiro de 2010; aceito: 28 de outubro de 2011)

\begin{abstract}
RESUMO: Neste trabalho, objetivou-se avaliar a emergência e o crescimento inicial de mudas de jatobá (Hymenaea courbaril. L) tratadas com bioestimulante vegetal (Stimulate ${ }^{\circledR}$ ) e sob sombreamento. Após escarificação, as sementes foram tratadas com o bioestimulante nas doses de 15,25 e $35 \mathrm{~mL}$ para cada $0,5 \mathrm{~kg}$ de sementes além da testemunha e a semeadura foi efetuada em bandejas de célula, contendo terra + areia + plantimax ${ }^{\circledR}$ na proporção de 1:1:1 (v:v). Foram avaliados a porcentagem de emergência e índice de velocidade de emergência, diâmetro, área foliar, altura da parte aérea e comprimento da raiz, massa seca de folhas, raiz e total, relação da massa seca da parte aérea/raiz, relação parte aérea/diâmetro, índice de qualidade de Dickson. As plântulas foram transplantadas aos 100 dias após a semeadura, para sacos de polietileno, de 10 x $20 \mathrm{~cm}$, contendo o mesmo substrato e mantidas sob 50 e $30 \%$ de luz e pleno sol. Foram avaliados a altura, diâmetro e clorofila aos 162, 178, 194, 210 e 226 dias após a semeadura e a taxa fotossintética, transpiratória e condutância estomática aos 226 dias após a semeadura. As doses utilizadas de bioestimulante proporcionaram inibição na germinação e no crescimento. A emergência foi maior sem o emprego de bioestimulante. Os maiores teores de clorofila foram observados em condições de $30 \%$ de luz, a menor fotossíntese a pleno sol. O bioestimulante nas doses mais elevadas, inibiu processos metabólicos, levando a um menor crescimento das mudas que, nessa fase inicial, podem ser cultivadas em condições de sombreamento.
\end{abstract}

Palavras chave: Hymenaea courbaril L., produçao de mudas, espécie nativa.

\section{JATOBÁ SEEDLINGS EMERGENCE AND GROWTH WITH THE USE OF BIOSTIMULANT AND SHADING}

\begin{abstract}
This research evaluated the emergence and initial growth of treated jatobá (Hymenaea coubaril L.) seedlings with vegetable biostimulant (Stimulate ${ }^{\circledR}$ ) and under shading. After scarification, seeds were treated with biostimulant in doses of 15 , 25 and $35 \mathrm{~mL}$ for every $0.5 \mathrm{~kg}$ of seeds, besides the control. The sowing was carried out in cell trays with substratum composed by soil + sand + plantimax ${ }^{\circledR}$ according to the proportion 1:1:1(v:v). The emergence speed index, diameter, leaf area, stem height, root lenght, leaf dry mass, root and total dry mass, stem/root dry mass ratio, stem /diameter ratio and Dickson Quality Index were evaluated. The seedlings were transplanted 100 days after sowing to $10 \times 20 \mathrm{~cm}$ polyethylene bags with the same substratum and they were kept under 50 and 30\% of light and full light. Height, diameter, chlorophyll were evaluated 162, 178, 194, 210 e 226 days after the sowing and stomatal conductance, photosynthetic and transpiration rate were evaluated 226 days after the sowing. The Stimulate doses used inhibited the seedlings emergence and initial growth. The emergence was higher without the use of the biostimulant. The greatest contents of chlorophyll were observed under 30\% of light, and the lowest photosynthesis under full sun. The biostimulant highest doses inhibited the metabolic process, leading to the lower growth of the seedlings that in this phase can be cultivated in shadow conditions.
\end{abstract}

Key words: Hymenaea courbaril L., seedling production, native specie.

\section{INTRODUÇÃO}

Hymenaea courbaril L. - Leguminosae conhecida como jatobá, tem importância florestal e ambiental pelo potencial que possui como planta fixadora e armazenadora de carbono, além de sua beleza paisagística (MELO; PÓLO, 2007). A maioria das espécies desse gênero possui algum valor econômico, pois fornece madeira de ótima qualidade, a casca e a seiva do tronco são usadas na fitoterapia popular, contendo valiosas resinas, os frutos são comestíveis e a casca é rica em tanino (FERREIRA; SAMPAIO, 1999).

Carvalho (2003) relatou que o jatobá apresenta lento crescimento vegetativo e suas sementes são duras com tegumento, impermeável à água o que dificulta ou retarda a germinação, podendo levar até 10 meses

${ }^{1}$ Bióloga - Secretaria Municipal de Educação de Dourados - Escola Professora Clori Benedetti de Freitas - 79805-021 - Dourados, MS lupiereza@yahoo.com.br

${ }^{2}$ Bióloga, Professora Dra. em Ciências dos Alimentos - Universidade Federal da Grande Dourados - Faculdade de Ciências Agrárias - Cx. P. 533 79804-970 - Dourados, MS - silvanascalon@ufgd.edu.br

${ }^{3}$ Bióloga, Dra. em Biologia Vegetal - Faculdade de Ciências Biológicas e Ambientais - Universidade Federal da Grande Dourados - Rodovia Dourados - Itahum, km 12 - 79804-970 - Dourados, MS - zefapereira@ufgd.edu.br

Cerne, Lavras, v. 18, n. 1, p. 127-133, jan./mar. 2012 
para germinar e com apenas $30 \%$ de germinação. Em sua revisão, observou que a dormência de tegumento das sementes de jatobá, pode ser superada por meio de escarificação química com ácido sulfúrico concentrado durante 30 minutos ou escarificação mecânica na região próxima ao embrião, ou ainda com imersão das sementes em água à temperatura ambiente por 7 a 10 dias.

$\mathrm{O}$ emprego de bioestimulantes tem otimizado os processos fisiológicos de germinação e crescimento das mudas em várias espécies. O bioestimulante originase pela mistura de dois ou mais biorreguladores com outras substâncias (aminoácidos nutrientes, vitaminas), e pode, em função de sua composição, concentração e proporção de substâncias, incrementar o crescimento e desenvolvimento vegetal, estimulando a divisão celular, podendo também aumentar a absorção de água e nutrientes pelas plantas (VIEIRA; CASTRO, 2001).

A intensidade luminosa, a temperatura, a concentração de $\mathrm{CO}_{2}$ e a umidade do solo são fatores que afetam a atividade fotossintética e, consequentemente, influem no crescimento das plantas. A luz é primordial não só por proporcionar energia para a fotossíntese, mas também por fornecer sinais que regulam o crescimento da planta. Estudos têm evidenciado a plasticidade fisiológica de espécies em relação à radiação fotossinteticamente ativa disponível, por meio de avaliações de crescimento inicial em relação a diferentes níveis de sombreamento.

Diante do exposto, conduziu-se este trabalho, com o objetivo de avaliar a emergência de plântulas e o crescimento no viveiro de mudas de jatobá (Hymenaea courbaril. L)

\section{MATERIAL E MÉTODOS}

Os frutos de $H$. courbaril foram coletados no chão em estádio de maturação completa em diversas matrizes na cidade de Dourados, MS. Foram beneficiados para remoção da polpa farinhosa e a extração das sementes. No Laboratório de Fisiologia Vegetal da Universidade Federal da Grande Dourados (UFGD), as sementes foram escarificadas com ácido sulfúrico pa por 30 minutos, para a superação da dormência tegumentar e, em seguida, lavadas em água corrente. Depois, as sementes foram submetidas ao tratamento com bioestimulante Stimulate $^{\circledR,}$ nas concentrações de $0,15,25,35 \mathrm{~mL}$ para cada $0,5 \mathrm{~kg}$ de semente. O Stimulate ${ }^{\circledR}$ possui a seguinte constituição: ácido indolbutírico $(0,005 \%)$, cinetina $(0,009 \%)$ e ácido giberélico $(0,005 \%)$ (STOLLER DO BRASIL, 1998).

Cerne, Lavras, v. 18, n. 1, p. 127-133, jan./mar. 2012
A semeadura foi feita em bandejas de 72 células, contendo, como substrato, a mistura de terra + areia + plantimax ${ }^{\circledR}$ na proporção volumétrica de 1:1:1 (v:v). Após a semeadura, foram acondicionadas em casa de vegetação e irrigadas diariamente. $\mathrm{O}$ experimento foi desenvolvido em duas etapas.

$\mathrm{Na}$ primeira etapa, avaliaram-se a porcentagem de germinação e as características de vigor das plântulas aos 40 dias após a semeadura. Adotou-se o delineamento inteiramente casualizado com quatro repetições de vinte sementes cada. As características avaliadas foram: porcentagem (E\%) e índice de velocidade de emergência (IVE), segundo Popinigis (1985), altura da parte aérea $(\mathrm{H}-\mathrm{cm})$ e comprimento da maior raiz $(\mathrm{CR}-\mathrm{cm})$ ambos medidos com régua milimetrada; diâmetro do coleto (D - mm), utilizando-se paquímetro digital com precisão de $0,01 \mathrm{~mm}$, massa seca de folhas (MSF), da raiz (MSR) e da total (MST) (mg/plântula) determinadas em estufa de circulação forçada a $60^{\circ} \pm 5^{\circ} \mathrm{C}$, até a obtenção de peso constante área foliar $\left(\mathrm{AF}-\mathrm{cm}^{2}\right)$ estimada com medidor de área foliar LI-COR modelo LI-3000, RPAR: relação da matéria seca da parte aérea com a matéria seca de raízes; RAD: relação comprimento da parte aérea com o diâmetro do coleto, DQI: índice de qualidade de Dickson obtido pela fórmula; $\mathrm{DQI}=[$ matéria seca total $/(\mathrm{RAD}+\mathrm{RPAR})]$ (DICKSON et al., 1960).

$\mathrm{Na}$ segunda etapa, avaliou-se o crescimento inicial da muda, tendo sido as plântulas, 100 dias após a semeadura, transplantadas para recipientes de polietileno de $10 \times 20 \mathrm{~cm}$, contendo como substrato a mistura de terra + areia + plantimax ${ }^{\circledR}(1: 1: 1)(\mathrm{v}: \mathrm{v})$ que foram colocados em três diferentes ambientes: $30 \%$ e $50 \%$ de interceptação de luz e a pleno sol. Foram realizadas cinco avaliações de altura da planta (H - cm), diâmetro do colo (D - mm), e a clorofila (Cl) com auxílio do SPAD 502, quando as mudas tinham 162, 178, 194, 210 e 226 dias após a semeadura e apenas uma avaliação de taxa fotossintética (A - $\mu$ mol $\left.\mathrm{m}^{-2} \mathrm{~s}^{-1}\right)$, transpiratória $\left(\mathrm{E}-\mathrm{Mmol} \mathrm{m} \mathrm{m}^{-2} \mathrm{~s}^{-1}\right.$ ), e condutância estomática (Gs - molm ${ }^{-2} \mathrm{~s}^{-1}$ ) com auxílio de medidor de fotossíntese LCi aos 226 dias, todas realizadas no período da manhã entre 9 e 10 horas.

$\mathrm{O}$ experimento foi conduzido em delineamento inteiramente casualizado em esquema fatorial 4 (doses de bioestimulante) x 3 (níveis de luz) com três repetições de dez mudas cada. Os dados foram submetidos à análise de variância e, havendo diferença significativa, as médias de sombreamento foram comparadas pelo teste de Tukey e as doses de bioestimulante, por análise de regressão, ambos a $5 \%$ de probabilidade. 


\section{RESULTADOS E DISCUSSÃO}

$\mathrm{Na}$ primeira etapa, a dose mais elevada de bioestimulante proporcionou menor porcentagem de emergência. Nas doses de 25 e $35 \mathrm{~mL}$, observaramse menores índices de velocidade de emergência e comprimento de raiz. Para as demais características avaliadas não houve diferença significativa entre os tratamentos utilizados. A emergência das plântulas do jatobá teve início aos quatorze dias e prolongou-se até quarenta dias após a semeadura, atingindo 79 e $58 \%$ de emergência na testemunha e tratamento com a maior dose de bioestimulante, respectivamente (Tabela 1).

Os resultados aqui encontrados sugerem que as maiores dosagens utilizadas de bioestimulante ou a forma de aplicação influenciaram negativamente a emergência de plântulas de jatobá e dose de $35 \mathrm{~mL}$ pode ter sido excessiva, causando inclusive inibição. Apesar de não haver diferença significativa entre a testemunha e as dose de 15 e $25 \mathrm{~mL}$ de bioestimulante, a porcentagem de emergência das plântulas foi maior no tratamento sem o uso do bioestimulante.

Esses resultados contrariam informações de Vieira e Castro (2001) que constataram ser o poder do bioestimulante dependente de sua composição, concentração e proporção de substâncias, podendo incrementar o crescimento vegetal, estimulando a divisão celular, podendo também aumentar a absorção de água e nutrientes pelas plantas.

Prado-Neto et al. (2007) observaram resultados significativos quando pré-embeberam sementes de (Genipa americana L.) por doze horas em Stimulate ${ }^{\circledR}(10 \mathrm{~mL}$ $\left.\mathrm{L}^{-1}\right)$ proporcionando maiores índices de velocidade de germinação, e também, maior comprimento total e das raízes em plântulas de jenipapo, em relação aos demais tratamentos, inclusive ao tratamento com $5 \mathrm{~mL}$ de Stimulate também contrariando os resultados da presente pesquisa. Embora os autores tenham observado melhores resultados na dosagem maior de Stimulate, a dosagem avaliada por eles foi inferior à dosagem empregada na presente pesquisa.

A massa seca avaliada e o índice de qualidade de Dickson apresentaram comportamento semelhante ao da porcentagem de emergência, índice de velocidade de emergência e comprimento de raiz, sendo menores na dose de $35 \mathrm{~mL}$ (Tabela 2).

O maior valor de RAD foi observado também na dosagem de $35 \mathrm{~mL}$ de bioestimulante semelhante aos valores da relação parte aérea / raiz. Maiores valores de RAD e RPAR podem indicar, se muito elevados, estiolamento das plantas, e menor crescimento do sistema radicular. Valores menores de RPAR indicam que a muda não teve bom desenvolvimento da parte aérea, sendo que, para valores maiores, o crescimento do sistema radicular pode ser insuficiente (MARANA et al., 2008). Esse desequilíbrio pode prejudicar a adaptação das mudas após o plantio em local definitivo, pelo fato de ser pequeno o sistema radicular, dificultando a absorção de água e a sustentação da muda no solo (LIMA et al., 2008).

$\mathrm{Na}$ segunda etapa, para a altura e diâmetro, não houve interação entre os níveis de luz e doses de bioestimulante. As mudas apresentaram crescimento linear da altura, alcançando, aos 226 dias após a semeadura, $22,2 \mathrm{~cm}$ (Figura 1a). Esses dados de altura corroboram informações de Carvalho (2003) e Takahashi e Martins (1993) de que o jatobá é uma espécie de crescimento lento. Em função das doses de bioestimulante, as mudas apresentaram maior altura, quando tratadas com $15 \mathrm{~mL}$ para $0,5 \mathrm{~kg}$ sementes (Figura 1b). Esses resultados indicam que as doses mais elevadas foram prejudiciais para o crescimento das plântulas e mudas de jatobá.

Tabela 1 - Emergência (E) e índice de velocidade de emergência (IVE), diâmetro (D), altura da parte aérea (H), comprimento de raiz (CR) e área foliar (AF) de plântulas de jatobá Hymenaea courbaril. L, 40 dias após a semeadura. UFGD, Dourados, 2008.

Table 1 - Emergence (E) and emergence speed index (IVE) of seeds, diameter (D), height (H) length of root (CR) and leaf area (AF) of jatobá (Hymenaea courbaril.L) seedlings 40 days after sowing. UFGD, Dourados, 2008.

\begin{tabular}{|c|c|c|c|c|c|c|}
\hline $\begin{array}{l}\text { Bioestimulante } \mathrm{mL} 0,5 \mathrm{~kg}^{-1} \\
\text { de sementes }\end{array}$ & E $(\%)$ & IVE & $\mathrm{D}(\mathrm{mm})$ & $\mathrm{H}(\mathrm{cm})$ & $\mathrm{CR}(\mathrm{cm})$ & $\mathrm{AF}\left(\mathrm{dm}^{2}\right)$ \\
\hline 0 & $79,33 \mathrm{a}$ & $0,935 \mathrm{a}$ & $0,07 \mathrm{a}$ & $11,43 \mathrm{a}$ & $20,16 a$ & $116,96 \mathrm{a}$ \\
\hline 15 & $76,00 \mathrm{a}$ & $0,900 \mathrm{a}$ & $0,07 \mathrm{a}$ & $11,00 \mathrm{a}$ & $18,50 \mathrm{a}$ & $111,14 \mathrm{a}$ \\
\hline 25 & $70,00 \mathrm{a}$ & $0,784 \mathrm{ab}$ & $0,07 \mathrm{a}$ & $10,83 \mathrm{a}$ & $15,25 \mathrm{ab}$ & $102,22 \mathrm{a}$ \\
\hline 35 & $58,66 \mathrm{~b}$ & $0,706 \mathrm{~b}$ & $0,05 \mathrm{a}$ & $10,58 \mathrm{a}$ & $14,83 \mathrm{~b}$ & $99,62 \mathrm{a}$ \\
\hline CV (\%) & 18,1 & 25,7 & 28,4 & 6,3 & 25,8 & 12,8 \\
\hline
\end{tabular}

Médias seguidas de mesma letra minúscula não variam estatisticamente entre si pelos testes de Tukey a 5\% de probabilidade.

Cerne, Lavras, v. 18, n. 1, p. 127-133, jan./mar. 2012 
Tabela 2 - Massa seca de folha (MSF), de raiz (MSR) e total (MST), relação parte aérea/raiz (RPAR), relação parte aérea/diâmetro (RAD) e índice de Qualidade de Dickson (DQI) de mudas de jatobá Hymenaea courbaril. L aos 40 dias após a semeadura. UFGD, Dourados, 2008.

Table 2 - Leaf dry mass (MSF), of root (MSR ) and total (MST), stem/root dry mass ratio, stem/diameter ratio and Dickson quality index (DQI) of jatobá (Hymenaea courbaril.L) seedlings 40 days after the sowing. UFGD, Dourados, 2008.

\begin{tabular}{lcccccc}
\hline $\begin{array}{l}\text { Bioestimulante } \mathrm{mL} 0,5 \mathrm{~kg}^{-1} \\
\text { de sementes }\end{array}$ & MSF (mg) & MST (mg) & MSR (mg) & RPAR & RAD & DQI \\
\hline 0 & $1073,66 \mathrm{a}$ & $2007,66 \mathrm{a}$ & $824,35 \mathrm{a}$ & $1,436 \mathrm{~b}$ & $16,91 \mathrm{~b}$ & $0,109 \mathrm{a}$ \\
15 & $1036,66 \mathrm{a}$ & $1943,66 \mathrm{a}$ & $801,22 \mathrm{a}$ & $1,419 \mathrm{~b}$ & $16,24 \mathrm{~b}$ & $0,110 \mathrm{a}$ \\
25 & $922,00 \mathrm{a}$ & $1717,33 \mathrm{a}$ & $705,33 \mathrm{a}$ & $1,435 \mathrm{~b}$ & $14,46 \mathrm{~b}$ & $0,108 \mathrm{a}$ \\
35 & $875,00 \mathrm{~b}$ & $1509,90 \mathrm{~b}$ & $549,91 \mathrm{~b}$ & $1,700 \mathrm{a}$ & $19,20 \mathrm{a}$ & $0,072 \mathrm{~b}$ \\
$\mathrm{CV}(\%)$ & 15,5 & 15,2 & 16,1 & 15,7 & 16,9 & 18,9 \\
\hline
\end{tabular}

Médias seguidas de mesma letra minúscula não variam estatisticamente entre si pelos testes de Tukey a 5\% de probabilidade
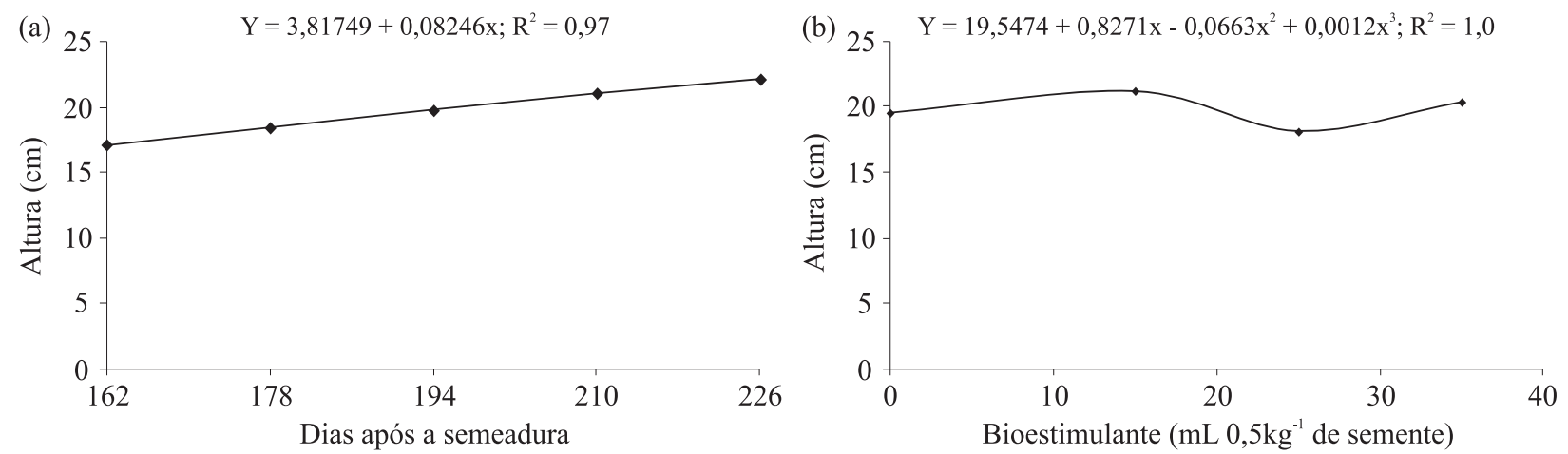

Figura 1 - Altura de mudas de jatobá (Hymenaea courbaril. L) em função dos dias após a semeadura e doses de bioestimulante. UFGD, Dourados, 2008.

Figure 1 -Seedling height of jatobá (Hymenaea courbaril.L) in function of days after sowing and doses of biostimulants. UFGD, Dourados, 2008.

O diâmetro das mudas também não variou entre as dosagens de bioestimulante utilizadas e apresentou um crescimento linear ao longo das avaliações, alcançando $3,14 \mathrm{~mm}$ aos 226 dias após a semeadura (Figura 2).

Com referência ao sombreamento, aos 226 dias após a semeadura, as mudas cultivadas a $50 \%$ de luz apresentavam maior altura, entretanto o diâmetro não variou entre os níveis de sombreamento, sendo menores nas mudas a pleno sol (Tabela 3 ).

Resultados semelhantes foram encontrados para jatobá do cerrado (H. courbaril L. var. stilbocarpa (Hayne) Lee et Lang.); fedegoso (Senna macranthera (Collad.) Irwin et Barn.) e moreira (Maclura tinctoria (L.) D. Don. ex Steud.) em condições de $0 \%, 70 \%$ e $50 \%$ de luz por Almeida et al. (2005) quando verificaram maiores alturas sob $50 \%$ da radiação solar.

Cerne, Lavras, v. 18, n. 1, p. 127-133, jan./mar. 2012

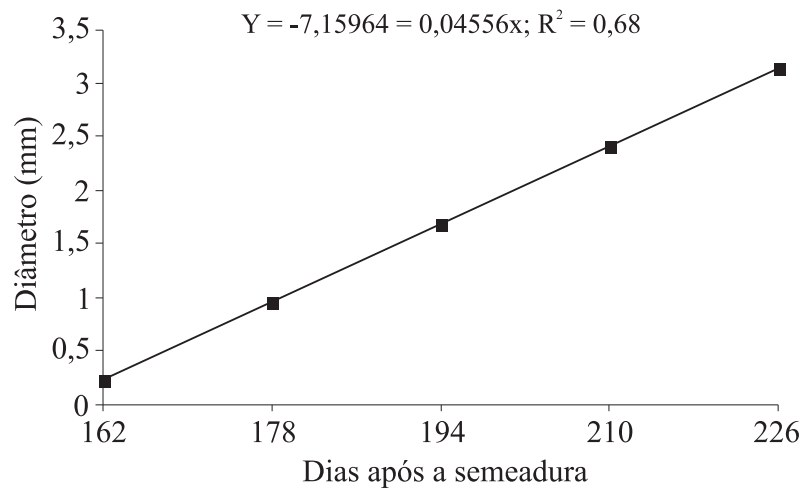

Figura 2 - Diâmetro de mudas de jatobá (Hymenaea courbaril.L) em função dos dias após a semeadura.

Figure 2 -Diameter of jatobá (Hymeneae courbaril. L) seedlings in function of days after sowing. UFGD, Dourados, 2008. 
Tabela 3 - Altura (H), diâmetro (D), clorofila (Cl), condutância estomática (Gs), taxa fotossintética (A) e transpiração (E) de mudas de jatobá (Hymeneae coubaril. L) aos 226 dias após a semeadura. UFGD, Dourados, 2008.

Table 3 -Height, diameter, chlorophyll, stomatal conductance, photosynthetic and transpiration rate of jatobá (Hymeneae courbaril L.) on 226 days after sowing. UFGD. Dourados, 2008.

\begin{tabular}{|c|c|c|c|c|c|c|}
\hline Níveis de luz & $\mathrm{H}(\mathrm{cm})$ & $\mathrm{D}(\mathrm{mm})$ & $\mathrm{Cl} \mu \mathrm{g} \mathrm{cm}^{2}$ & Gs $\left(\mathrm{molm}^{-2} \mathrm{~s}^{-1}\right)$ & $\mathrm{A}\left(\mu \mathrm{mol} \mathrm{m} \mathrm{m}^{-2} \mathrm{~s}^{-1}\right)$ & 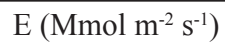 \\
\hline $30 \%$ & $22,58 \mathrm{~b}$ & $2,512 \mathrm{a}$ & $44,37 \mathrm{a}$ & $0,092 \mathrm{a}$ & 4,441 a & $1,205 \mathrm{~b}$ \\
\hline $50 \%$ & $25,75 \mathrm{a}$ & $2,705 \mathrm{a}$ & $32,77 \mathrm{~b}$ & $0,061 \mathrm{~b}$ & $4,836 \mathrm{a}$ & $1,575 \mathrm{ab}$ \\
\hline Pleno Sol & $21,09 \mathrm{~b}$ & $2,219 \mathrm{~b}$ & $31,28 \mathrm{~b}$ & $0,056 \mathrm{~b}$ & $4,129 \mathrm{~b}$ & $2,421 \mathrm{a}$ \\
\hline $\mathrm{CV}(\%)$ & 16,6 & 20,3 & 10,6 & 37,59 & 31,13 & 36,63 \\
\hline
\end{tabular}

Médias seguidas de mesma letra minúscula na coluna não variam estatisticamente entre si pelos testes de Tukey a 5\% de probabilidade.

O teor de clorofila foi maior nas mudas sob menor disponibilidade de luz (Tabela 3), aumentando até os 194 dias, reduzindo em seguida, apresentado um crescimento quadrático. Nas demais condições de cultivo houve redução durante o crescimento das mudas (Figura 3a).

Geralmente, a clorofila e os carotenóides tendem a aumentar com a redução da intensidade luminosa (FERRAZ; SILVA, 2001; FONTES; SILVA, 2001), sendo um recurso para otimizar a fotofosforilação e, consequentemente, a produção de energia. Resultados semelhantes também foram observados em plantas jovens de (camboatã) Cupania vernalis Camb., experimento que demonstrou que os maiores valores de clorofila foram observados em plantas submetidas a 50 e $70 \%$ de sombreamento comparados com as mudas crescidas a $30 \%$ e pleno sol (LIMA JÚNIOR et al., 2006), e em (jequitibárosa), Cariniana legalis (Mart.) Kuntzs submetidas aos níveis de 100, 70, 64 e 34\% de luminosidade, sendo que, níveis de sombreamento mais elevados, proporcionaram maior teor de clorofila (REGO; POSSAMAI, 2006).

Ao longo das avaliações, sob 30\% de luz, as mudas mostraram crescimento linear no teor de clorofila e com o aumento nas doses do bioestimulante, enquanto que, as cultivadas a pleno sol apresentaram maior teor quando tratadas com $35 \mathrm{~mL}$ de bioestimulante. Sob 50\% de luz não foi observado um padrão no teor de clorofila em relação às doses de bioestimulante (Figura 3b).

Não houve interação significativa entre os tratamentos para condutância estomática, taxa fotossintética e transpiração das plantas e nem efeito das doses de bioestimulante. A condutância foi maior sob 30\% de luz, a transpiração foi menor e não variou entre os dois níveis de sombreamento, sendo que e a fotossíntese foi maior entre os níveis de sombreamento, não variando entre si (Tabela 3).
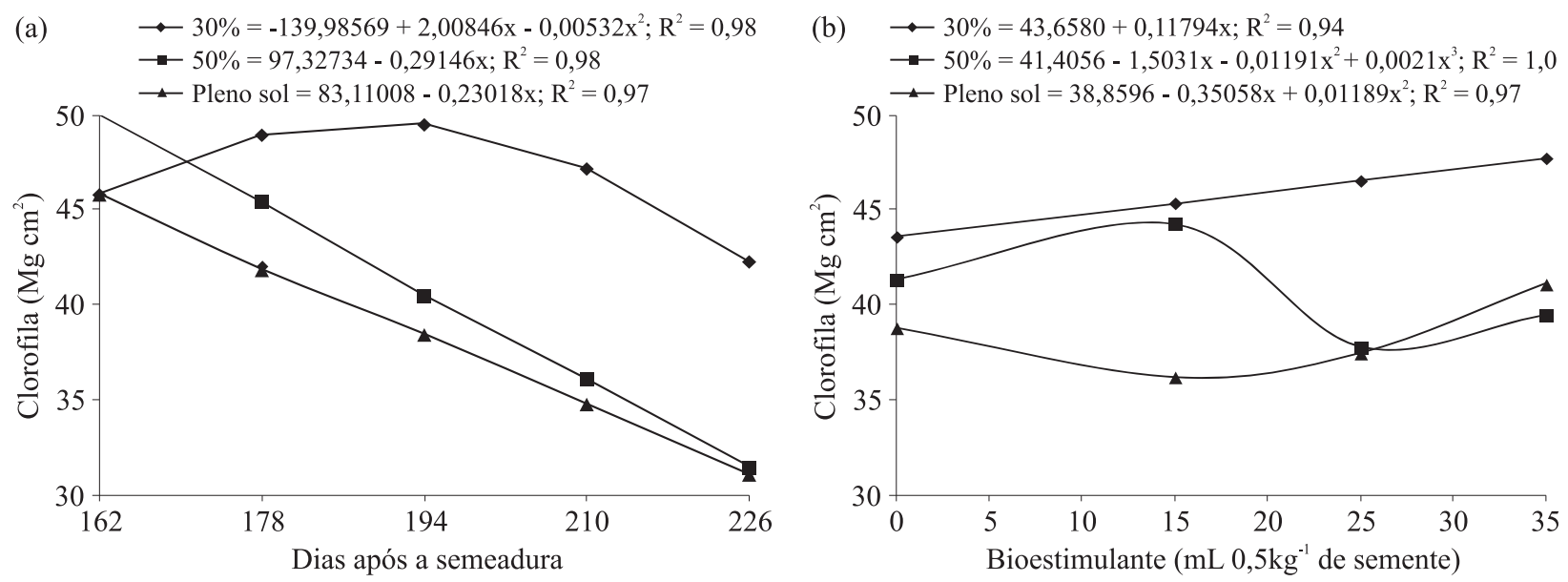

Figura 3 - Clorofila de mudas de jatobá (Hymenaea courbaril. L) em função dos dias após a semeadura e doses de bioestimulante. UFGD, Dourados, 2008.

Figure 3 - Chlorophyll of jatobá (Hymenaea courbaril. L) seedlings in function of days after sowing and doses of biostimulants. UFGD, Dourados, 2008.

Cerne, Lavras, v. 18, n. 1, p. 127-133, jan./mar. 2012 
Esses resultados podem ser atribuídos ao fato de que, em condição de maior sombreamento (30\% de luz), a temperatura chega a ser até $5^{\circ} \mathrm{C}$ menor (FONSECA et al., 2002) que a pleno sol, levando a menor taxa de evaporação do solo e de transpiração das folhas, o que pode manter os estômatos abertos por mais tempo. A queda da fotossíntese a pleno sol pode ser atribuída a algum mecanismo de fotoinibição (DIAS; MARENCO, 2006).

O comportamento transpiratório de mudas em diferentes disponibilidades de luz mostrou-se variável. Resultados semelhantes aos observados para o jatobá também foram registrados por Welander e Otosson (2000) para Quercus robur L., (carvalho) trabalho que mostrou aumento da irradiância, promovendo maiores taxas de transpiração. Entretanto, Lima Júnior et al. (2006) não verificaram diferenças na transpiração de plantas jovens de Cupania vernalis Camb. submetidas a diferentes níveis de sombreamento $(0,30,50$ e $70 \%)$.

O crescimento das mudas foi reduzido sob cultivo a pleno sol, entretanto, a 30\% de luz, a disponibilidade luminosa pode não ter sido suficiente para a planta produzir os fotoassimilados necessários para suprir a demanda de crescimento da planta. Os maiores valores numéricos de altura, diâmetro e taxa fotossintética sob $50 \%$ de luz podem significar um melhor aproveitamento e translocação dos fotoassimilados.

\section{CONCLUSÕES}

O bioestimulante na dose de $35 \mathrm{~mL} 0,5 \mathrm{~kg}$ de semente inibe o processo de germinação e a qualidade da muda de jatobá, aos 40 dias após a semeadura. Após 100 dias, as doses de bioestimulante não alteram o crescimento e nem o metabolismo das mudas.

Até os 226 dias, as mudas de jatobá podem ser mantidas em condições de 30 ou $50 \%$ de luz.

\section{REFERÊNCIAS}

ALMEIDA, S. M. Z. et al. Alterações morfológicas e alocação de biomassa em plantas jovens de espécies florestais sob diferentes condições de sombreamento. Ciência Rural, Santa Maria, v. 35, n. 1, p. 62-68, 2005.

CARVALHO, P. E. R. Espécies arbóreas brasileiras. Brasília: Embrapa Informação Tecnológica; Colombo: Embrapa Florestas, 2003. 1039 p.

DIAS, D. P.; MARENCO, R. A. Photoinhibition of photosynthesis in Minquartia guianensis and Swietenia

Cerne, Lavras, v. 18, n. 1, p. 127-133, jan./mar. 2012 macrophylla inferred by monitoring the initial fluorescence. Photosynthetica, Prague, v. 44, n. 2, p. 235-240, 2006.

DICKSON, A.; LEAF, A. L.; HOSNER, J. F. Quality appraisal of white spruce and White pine seedling stock in nurseries.

Forest Chronicle, Mattawa, v. 36, p. 10-13, 1960.

FERRAZ, K. K. F.; SILVA, D. M. Avaliação ecofisiológica do crescimento inicial de espécies florestais usadas na recuperação de áreas degradadas: II., Calliandra calothyrsus Meisn. In: CONGRESSO NACIONAL DE FISIOLOGIA, 8., 2001, Ilhéus. Anais... Ilhéus, 2001. CD-ROM.

FERREIRA, C. A. C.; SAMPAIO, P. de T. B. Jatobá Hymenaea courbaril. In: CLAY, J. W.; SAMPAIO, P. de T. B.; CLEMENT, C. R. Biodiversidade Amazônica: exemplos e estratégias de utilização. Manaus: UFAM, 1999.

FONSECA, P. V.; VALERI, S. V.; MIGLIORANZA, E. Padrão de qualidade de mudas de Trema micrantha (L.) Blume, produzidas sob diferentes períodos de sombreamento. Revista Árvore, Viçosa, v. 26, n. 4, p. 515-523, jul./ago. 2002 .

FONTES, R. V.; SILVA, D. M. Avaliação ecofisiológica do crescimento inicial de Piptadenia adiantoide (Spreng.) Macbr., espécie florestal usada na recuperação de áreas degradadas. In: CONGRESSO NACIONAL DE FISIOLOGIA, 8., 2001, Ilhéus. Anais... Ilhéus, 2001. CD-ROM.

LIMA, J. D. et al. Efeitos da luminosidade no crescimento de mudas de Caesalpinia ferrea Mart. ex Tul. (Leguminosae, Caesalpinoideae). Acta Amazonica, Manaus, v. 38, p. 5-10, 2008.

LIMA JÚNIOR, E. C. et al. Aspectos fisioanatômicos de plantas jovens de Cupania vernalis Camb. submetidas a diferentes níveis de sombreamento. Revista Árvore, Viçosa, v. 30, n. 1, p. 33-41, jan./fev. 2006.

MARANA, J. P. et al. Índices de qualidade e crescimento de mudas de café produzidas em tubetes. Ciência Rural, Santa Maria, v. 38, p. 39-45, 2008.

MELO, N. C.; PÓLO, M. Sobrevivência e Germinação de sementes de Hymenaea courbaril L. In: CONGRESSO DE ECOLOGIA DO BRASIL, 2007, Caxambu. Resumos... Caxambu, 2007. 
POPINIGIS, F. Fisiologia da semente. Brasília: Agiplan, 1985. 289 p.

PRADO NETO, M. et al. Germinação e sementes de jenipapeiro submetidas à pré-embebição em regulador $\mathrm{e}$ estimulante vegetal. Ciência e Agrotecnologia, Lavras, v. 31, n. 3, p. 693-698, maio/jun. 2007.

REGO, G. M. R. T. et al. Efeito do sombreamento sobre o teor de clorofila e crescimento inicial do Jequitibá-rosa. Boletim de Pesquisa Florestal, Colombo, n. 53, p. 179-194, 2006.

STOLLER DO BRASIL. Stimulate ${ }^{\circledR}$ Mo em hortaliças: informativo técnico. Cosmópolis, 1998.
TAKAHASHI, L. Y.; MARTINS, S. S. Desenvolvimento de espécies florestais do norte do Paraná a céu aberto. In: CONGRESSO FLORESTAL BRASILEIRO, 7. 1993, Curitiba. Anais... Curitiba: Sociedade Brasileira de Silvicultura, 1993. p. 758.

VIEIRA, E. L.; CASTRO, P. R. C. Ação de bioestimulante na germinação de sementes, vigor de plântulas, crescimento radicular e produtividade de soja. Revista Brasileira de Sementes, Brasília, v. 23, n. 2, p. 169-174, 2001.

WELANDER, N. T.; OTOSSON, B. The influence of low light, droughtand fertilization on transpiration and growht in young seedllings of Quercus robur. Forest Ecology and Management, Amsterdam, v. 127, n. 1/3, p. 139-151, 2000.

Cerne, Lavras, v. 18, n. 1, p. 127-133, jan./mar. 2012 